\title{
Inheritance and Innovation of Chinese Traditional Culture in Modern Design
}

\section{Guo CHEN}

Art Department, City College, Wuhan University of Science and Technology, East lake ecological tourism district, Wuhan, Hubei, China, 430083

\author{
icarolstyle@qq.com
}

Keywords: Chinese Traditional Culture, Naturalism, Minimalism, Bionic.

\begin{abstract}
This article is finding the relationship between traditional culture and modern design. Through the analysis of four concepts of creating things in Chinese traditional culture, we are finding four ways to combine with past and present. To design industrial products with Chinese characteristics, we need to inherit and develop Chinese traditional culture for modern design.
\end{abstract}

\section{Introduction}

Chinese traditional culture has a long history, it is profound and intellectual. How to reference it for modern design? This article gives four analysis of creating things in Chinese traditional culture to find the relationship between traditional culture and modern design, in order to make the past serve the present.

\section{The Naturalism in Chinese Traditional Culture}

Chinese Taoism claims "harmony between human being and nature", in this proverb, it means people should be abided by the law of nature. The Taoist doctrine that "Man must conform to the earth, earth to heaven, heaven to Tao and Tao to nature" tells us that "nature" is the fundamental law of the universe and human society [1].

In the Chinese design concept, good design should be free of natural, it is flexible and full of changes. "Simplicity being the non-debatable beauty", the aesthetic statement raised by Zhuang Zi has been the aesthetic character and standard held by Tao School. So in Chinese culture the relationship of man and nature is not the opposite, it is intimacy and harmonious. For example, the design of Chinese garden usually adopts natural curve plan. In the garden, rockery, stone, pavilion and stream, are all imitated of natural. Although made by people, there are seldom adopted symmetric structure. They look as natural formation.

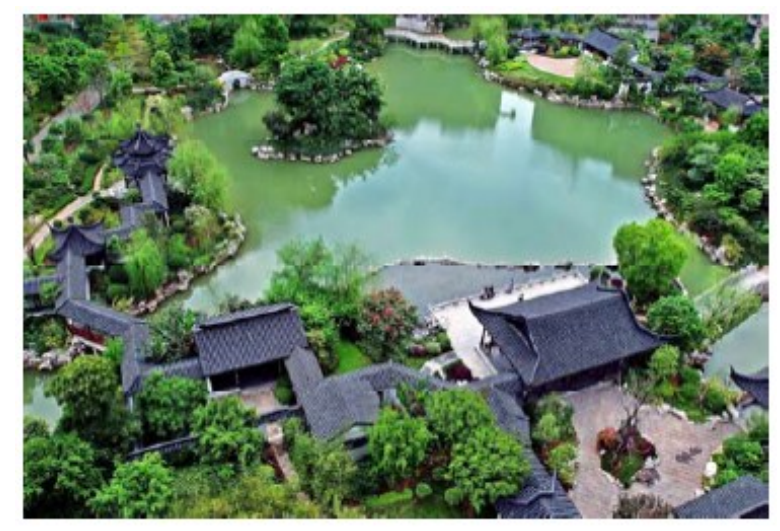

Figure. 1 The aerial view of Suzhou garden 


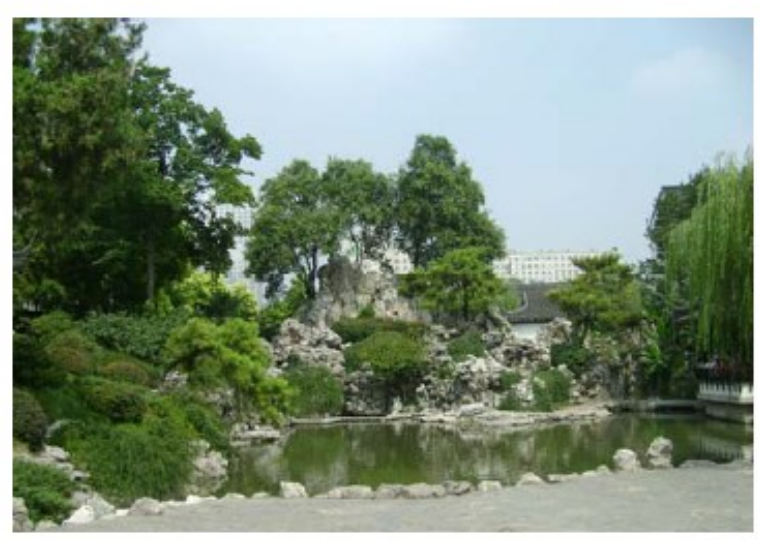

Figure. 2 A rockery in Suzhou garden

The relationship between human and nature provides two aspects of modern design:

(1)Modern design should respect the objective law of things. We can obtain inspiration from the nature, respect the material attribute of itself, at the same time, respect human nature and social attribute.

(2)Use the design concept by "The harmonious of human and nature" to coordinate man - machine - environment system, such as, integrate science, economic, society and art into the modern design, in order to achieve the purpose of sustainable development.

\section{The Minimalism in Chinese Traditional Culture}

In ancient times, Chinese people like live a quite life, use simple implements and consider elegant thing is beautiful. As early as in ancient China people put forward against unnecessary decoration of design, they put function in the first place. "Implements with no decoration" or "Best quality and less decoration", as the same meaning as "less is more" that said by German modernist designer Mies van der rohe. For example, the design of Ming-style furniture is elegance and neat, it uses the mortise and tenon joint structure to combination of all the parts, do not use a nail riveting. According to different parts of the furniture, they use different mortise and tenon joint structures. By the way, ming-style furniture is rarely decoration, it uses the form of material itself.

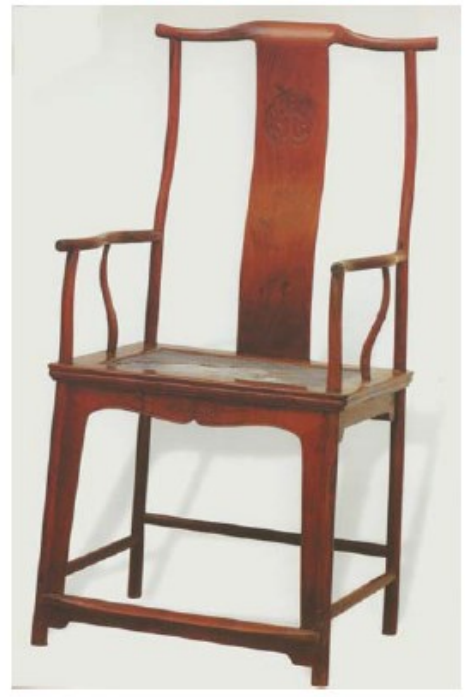

Figure. 3 Ming-style furniture 


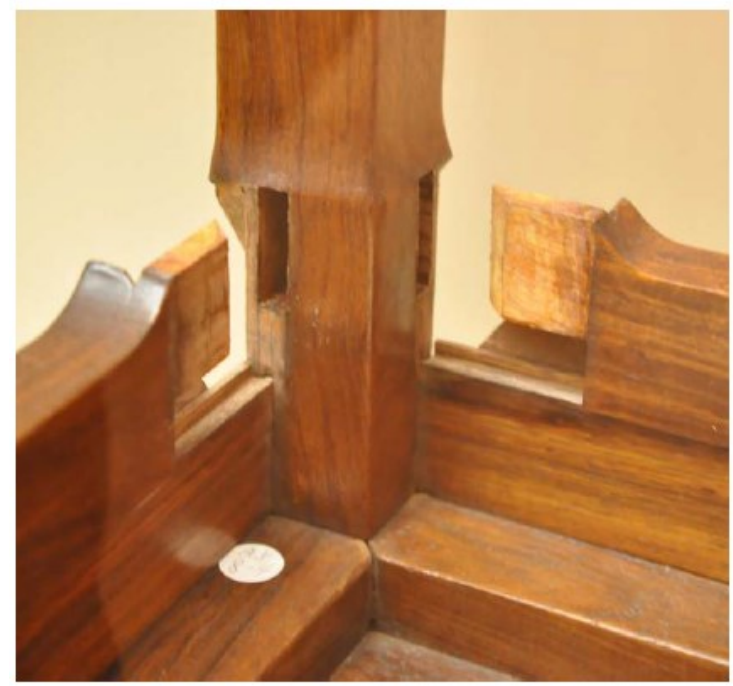

Figure. 4 Mortise and tenon joint structure

Vigorous concise and fluent line are the essence of modern functionalism and minimalist design. The minimalism in Chinese traditional culture is based on the personal aesthetic ideal, it promotes people's status in the material world-----material is used and served for people. In the material first, commercial competitive economy society, we should get inspiration from Chinese traditional culture to design concise and practical things.

Confucianism About the "Gentle" design aesthetics means good design should be based on function, at the same time, pay attention to human nature [2]. So, in modern design, we can not abandon the tradition to pursue the modernism" Form follows function", We should use modern design method combined with the Chinese traditional culture to create a new national style.

\section{"Observing Things to Get Sense" in Chinese Traditional Culture}

"Observing things to get sense" is one of the most important method to know the world in ancient China, "Observing things" means survey the universe and" get sense" means extract the inherent rule. With this method, the Chinese ancients observe objective phenomenon to analyze inherent rule and perform the rule on design things. For example, the form of Qin dynasty coin is circular outside and spare inside, and this form is according to the cognitive view of the Chinese ancients that the sky is round and the earth is square. Another example is the Song dynasty porcelain, the color of it is usually cyan or white, and is few decorated. With smooth shape and pure texture, the cyan porcelain looks like jade and the white one looks like snow.

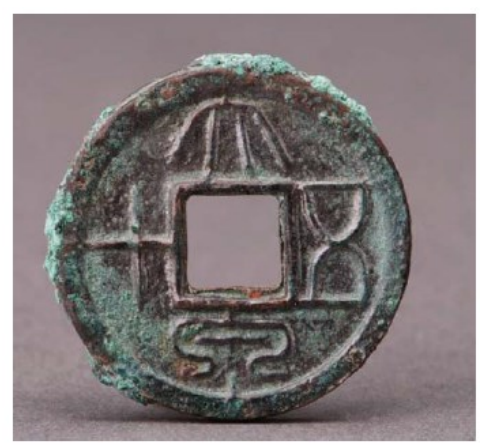

Figure. 5 Qin dynasty coin 


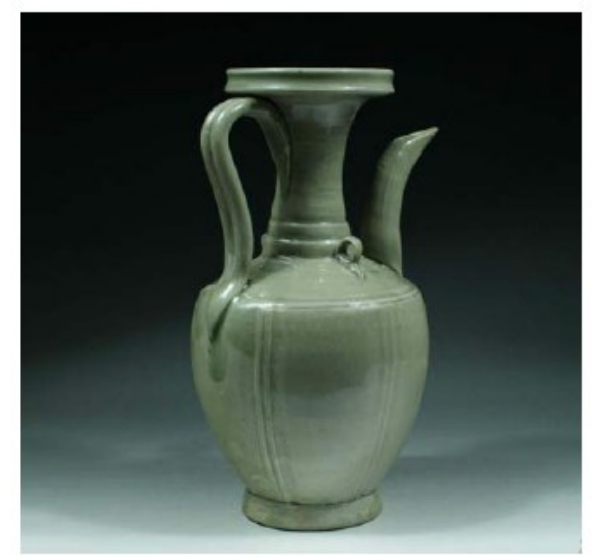

Figure. 6 Cyan porcelain of Song dynasty

The nature beauty without decoration is the Chinese ancient pursuit of elegant which is free from vulgarity. With the wide application of new scientific technology, national traditional culture is in the impact of modern civilization. The difference of people's lives are decrease, and design style becoming the internationalization. In this case, the cultural connotation becomes the essence of design that can not be ignored.

"National is the world" means people are more and more focus on product with deep cultural connotation. How to join the Oriental artistic conception in modern products? "Observing things to get sense" in Chinese traditional culture has important significance for modern design. We can use the way of metaphor, hint, symbol, quote and simulation to rich design language and enhance the cultural quality of design in order to meet the diversified spiritual needs and improve the quality of life.

\section{The Bionic Concept for Design in Chinese Traditional Culture}

One concept of Chinese Taoism is "The nature lives with me in symbiosis, and everything is with me as a whole." In the process of changing nature, the Chinese ancients take the nature as a teacher and learn from it. They do not want to conquer the nature or control, they obey and absorb the rule of it. Review the Chinese ancient civilizations, there are many traditional things designed by animal forms, such as rabbit shape lamp, sheep shape lamp and pig shape pot. One of the most famous is "Changxing Palace" Lamp . The "Changxing Palace" Lamp is a very important bronze lamp in the Han dynasty, the integral shape is a palace maid with a lamp in hand, her cuff is used for smoke pipe and her body for keeping water to absorb lampblack. It has very high value in aesthetics and practicality, sculpt and color, perception and rationality.

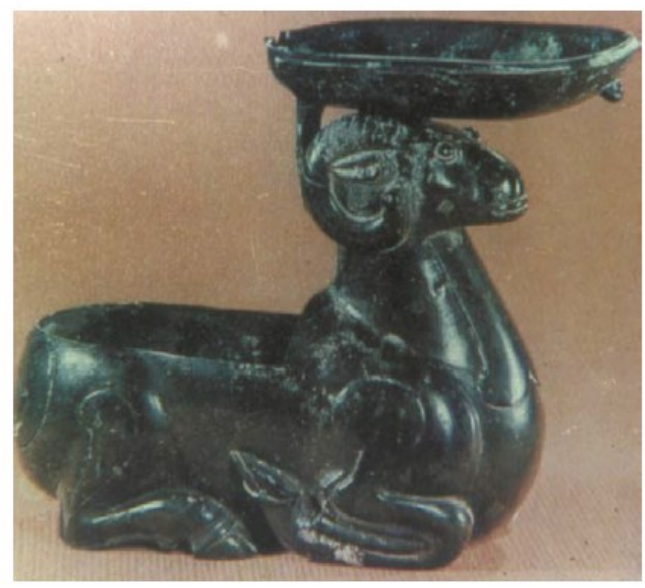

Figure. 7 Sheep shape lamp 


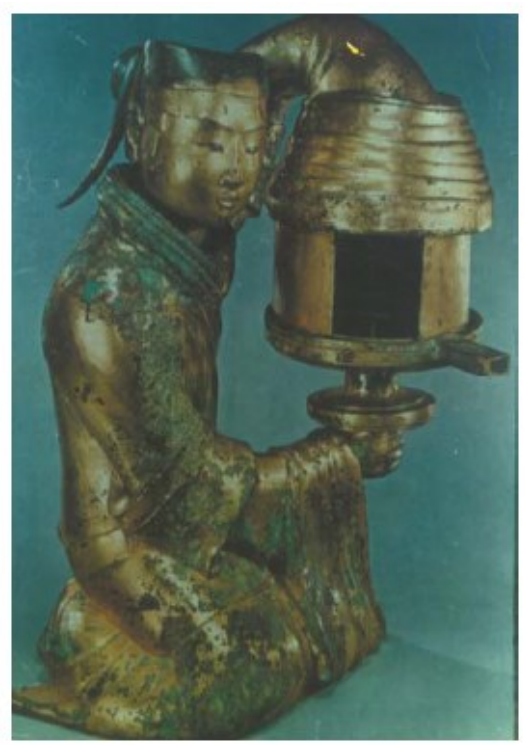

Figure. 8 "Changxing Palace” Lamp

"The nature gives birth to everything, and each has its use". A large number of cases are identified about people's creative imitations to the natural life's shape and function. In the ancient times, they seem to realize the true meaning of their own survival, development and progress from the natural ecosystem. With the high-speed development of modern industrialization, modern civilization changed, mechanized productions are damaging our living environment. Based on this fact, learning from nature becomes more and more important. The bionics is able to provide product shape from science and nature, in order to create things with aesthetic principles about structure, shape and color.

\section{Conclusion}

"Harmony" is the center of Chinese Traditional culture which reflected in the relationship between people and things, it is the unification of mind and things, material and skill and beauty and use. To design industrial products with Chinese characteristics, we need to be combined with traditional Chinese culture, inherit and develop it for modern design, in order to realize the harmony between people, society and nature.

\section{References}

[1] Chen Guying, The research of Taoist culture research, SDX Joint Publishing, 2015

[2] Qian Mu, A new interpretation of the analects of Confucius, SDX Joint Publishing, 2002

[3] Li Zehou, the History of Beauty, SDX Joint Publishing, 2014

[4] Li Yanzu, the Beauty of Creation, Renmin University of China Publishing, 2000.

[5] Huang Shi, Chinese Traditional Culture in Architecture article, Beijing Institute of Technology. Beijing (100081).

[6] Yang Xianyi, By Chinese Tradition Divine Creative Force Culture Harmonious Thought article, China Water Transport. 2007

[7] Traditional Chinese Culture Community Forum on http://www.ctwhlt.org 